\title{
Histopathology of the Kidney in Adult Mice with Heritable Renal Hypoplasia
}

\author{
S. Lozanoff, ${ }^{*}$ M. Kuroyama, ${ }^{*}$ C. Bates, ${ }^{* *}$ and W. Ma*
}

* Department of Anatomy and Reproductive Biology, University of Hawaii School of Medicine, 1960 East-West Road, Honolulu, HI 9682

** Department of Pediatrics, 700 Children's Drive, Ohio State University School of Medicine, Columbus, $\mathrm{OH} 43205$

The $3 \mathrm{H} 1 \mathrm{Br}$ mouse fetus displays renal hypoplasia that is associated with a deficient nephrogenic zone and the mutation is located on murine chromosome 17 [1]. The purpose of this study was to characterize histopathological features of the $3 \mathrm{H} 1 \mathrm{Br} /+$ adult kidney.

Adult inbred $3 \mathrm{H} 1$ and out bred $3 \mathrm{H} 1 \times$ Balb $+/+$ and $\mathrm{Br} /+$ mice were selected for study. Normal and mutant mice $(\mathrm{n}=12)$ between 2 and 6 months of age were selected randomly, weighed, killed, and kidneys were excised and weighed. Tissues were immersion fixed, paraffin embedded, and serially sectioned. Alternate sections were routinely stained with hematoxylin and eosin (HE) for generalized observations. Sections were stained to observe specific regions of the nephron using TP derived lectin (proximal tubule), Tamm-Horsfall protein (thick ascending loop of Henle) and aquaporin-2 (collecting tubules). Additional kidney sections were immunostained with antibodies to Na,K-ATPase, endothlin-1 (ET-1) and endothelin receptors (ETA, ETB) as indicators of the disease process. Kidney tissue sections were also collected for observations with electron microscopy. Thick sections were stained with methylene blue and observed with a compound microscope while thin sections were processed for TEM observations.

Adult mutant mice had significantly smaller kidney to body weight ratios $(\mathrm{p}<.01)$ compared to normal mice. Kidney tissue sections from $\mathrm{Br} /+$ mice stained with $\mathrm{HE}$ showed cortical tissue with a reduced width and glomerular number. Staining of the nephron components indicated that the proximal tubule, ascending thin loop of Henle and collecting tubules were intact (Fig. 1). However, other mutant mice displayed severe renal disease including distended tubules and enlarged glomeruli (Fig. 2A,B). Immunostaining revealed increased densities of Na,K-ATPase, ET-1, ETA and ETB indicative of chronic renal disease. Electron micrographs demonstrated attenuated glomerular filtration barriers (Fig. 2C,D). Results from this study demonstrate that the $\mathrm{Br}$ mutation results in renal hypoplasia that is associated histopathological features consistent with chronic renal failure. However, the rate of onset appears variable.

\section{References}

[1] S. Lozanoff et al., J Histochem Cytochem (2001) 1081.

[2] Supported by R01 DK64752-01. 

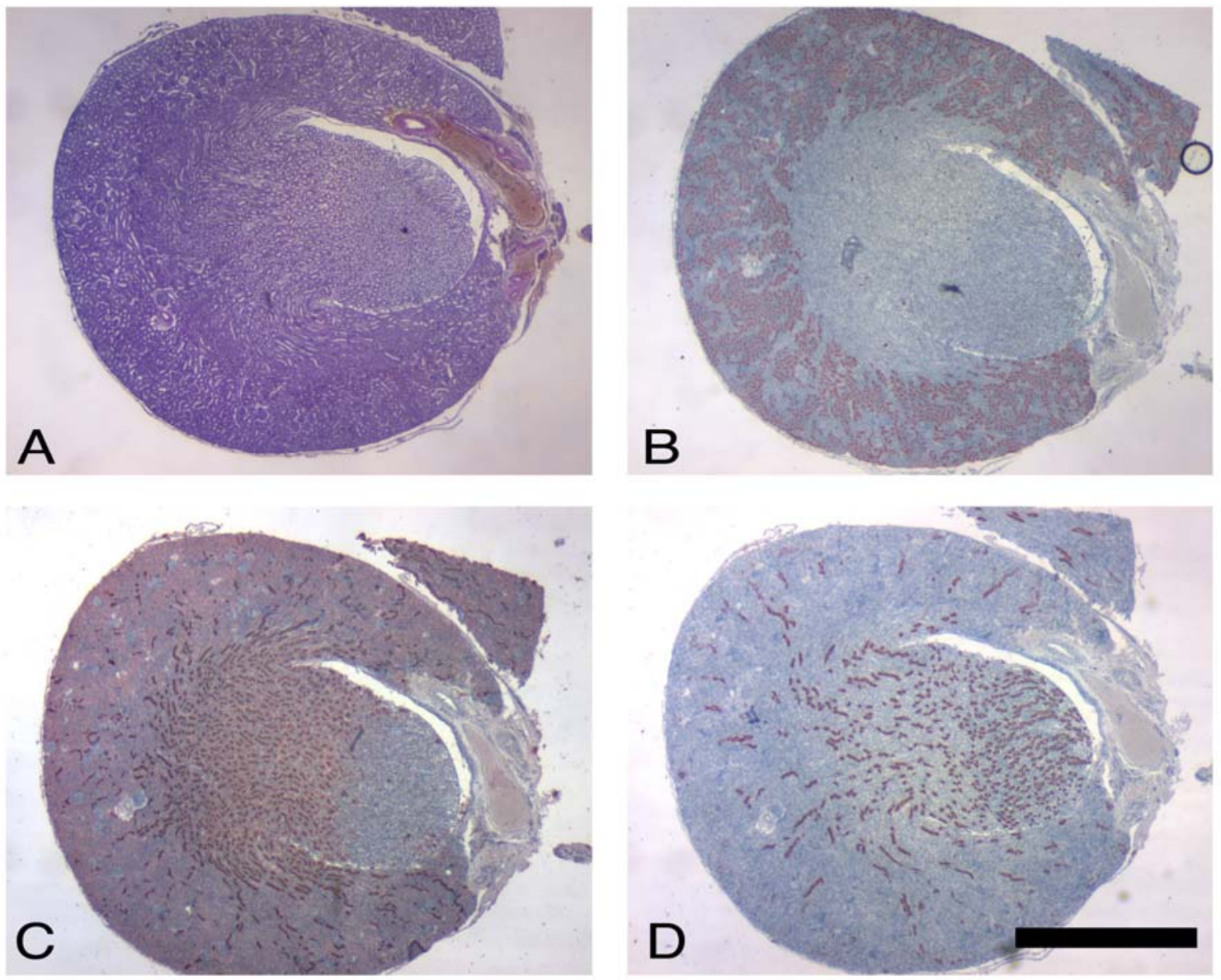

Fig. 1. Adult $\mathrm{Br} /+$ kidney with reduced cortical width (A), but normal appearing proximal tubules (B), loops of Henle (C) and collecting tubules (D). Bar $=2.0 \mathrm{~mm}$.
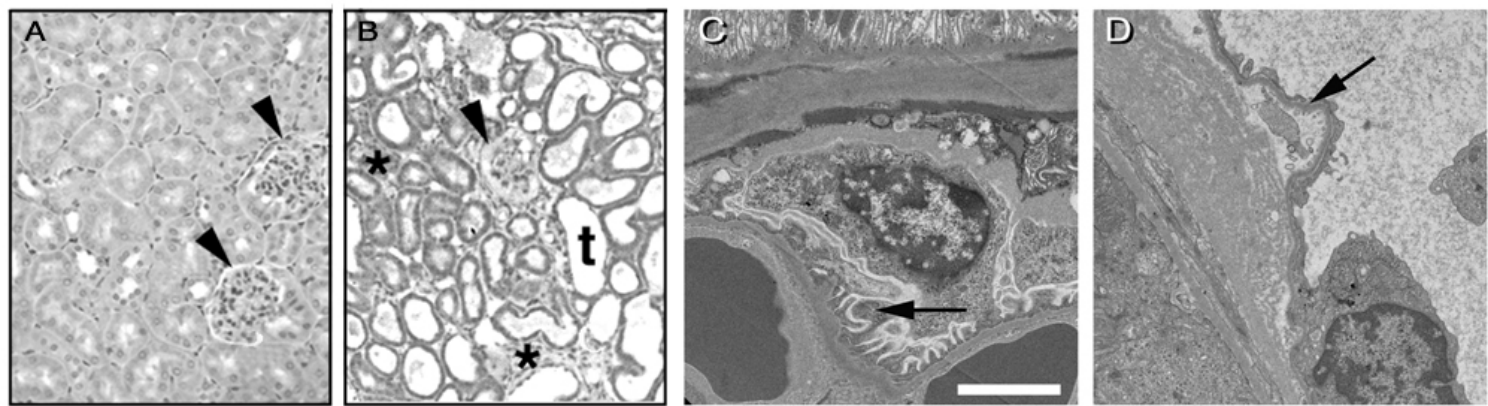

Fig. 2. Normal cortical structures of the $+/+$ kidney (A) including glomeruli (arrowheads) while affected $\mathrm{Br} /+$ kidneys showed distended tubules $(\mathrm{t})$, sclerotic glomeruli (arrowheads), and increased cellularity between tubules (asteriks). Electron micrographs $(\mathrm{C})$ of $+/+$ animals showed a normal glomerular filtration barrier while affected $\mathrm{Br} /+$ animals demonstrated a thin and attenuated filtration barrier (arrow) with an absence of definitive pedicels. 